What would have happened in Ireland where frosts are late or only slight we do not know, since no tests have been carried out in the southwest; and in any event the incidence of blight might now obscure West; and in any event the incidence of blight might now obscure
the issue. For Dr. van der Plank to state, therefore, that the Andean potatoes would not have been at a disadvantage when grown in Ireland potatoes would not have been at a disadvantage when grown in Ireland in the early seventeenth century is pure supposition, since there is not a single piece of evidence to support this view. Evidence of high yields in England was not available until about two hundred years later,

Whatever may be Dr. van der Plank's opinion, we still feel ourselves perfectly justified in maintaining that the extreme short-day reaction of most of the Andean potatoes was an undesirable feature, and one which had to be removed before the potato crop could assume the importance it has to-day. It might be mentioned that while both Andean potatoes and European varieties have hereditary capacities for high yield, in the former case the greatest single limiting factor under British conditions is the day-length requirement, while in the latter case cultural conditions and disease play a greater part. Never theless, the yield obtained from the early introductions would be by no means negligible, but would be sufficient to encourage their culture as soon as farming conditions became suitable.

Imperial Bureau of Plant Breeding and Genetics

$$
\begin{aligned}
& \text { J. G. HAWKES } \\
& \text { C. M. DRIVER }
\end{aligned}
$$
School of Agriculture, Cambridge.

${ }^{1}$ Nature, 15\%, 591 (1946).

'Driver, C. M., and Hawkes, J. G., Bull, Imp. Bur. Plant Breed. and Genet. (1943), 36 .

\section{A New Route to 7-Dehydrocholesterol, Provitamin $D_{3}$}

IN 1935, Windaus, Lettré and Schenck ${ }^{1}$ described the preparation from cholesterol (I) of 7-dehydrocholesterol (III), which on irradiation gave a highly antirachitic product (vitamin $\mathrm{D}_{3}$ ), later ${ }^{2}$ shown to be identical with the naturally occurring vitamin $\mathbf{D}$ isolated from tunny liver oil. The original route to provitamin $D_{3}$, giving an overall conversion from cholesterol of about 4 per cent, has since been employed for the synthesis of several related dehydrosteroids ${ }^{3}$, but it has not been materially improved, although some useful minor modifications have been described ${ }^{4}$. Claims ${ }^{5}$ have been made for alternative and improved methods, but, so far as we are aware, none of these has improved methods, but, so

We have now discovered that the reaction of N-bromosuccinimide ${ }^{6}$ We have now discovered that the reaction of $\mathrm{N}$-bromosuccinimide
or related compounds with cholesteryl acetate gives a product from

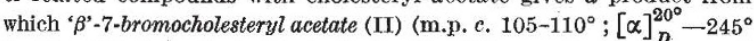
in chloroform) can be isolated. On heating this monobromo compound with diethylaniline, hydrogen bromide is eliminated;

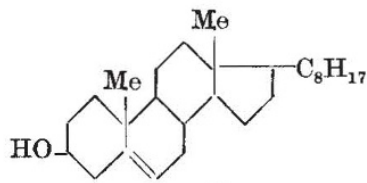

(I)

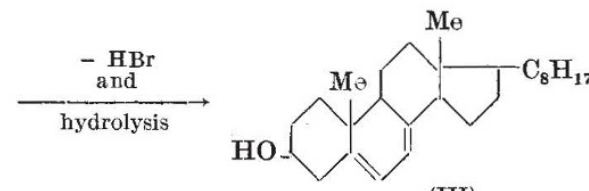

(III)

after hydrolysis of the product, 7-dehydrocholesterol (III) can be isolated, either by chromatography or as its readily purifled $3: 5$ dinitrobenzoate. Under suitable conditions cholesterol can be converted by this route into its 7-dehydro-derivative in yields of about 30 per cent.

Detailed accounts of this process, of its application to other steroid derivatives, and of the characterization and reactions of the 7-bromosteroids, will be published elsewhere ${ }^{7}$.

Imperial College of Science and Technology, London, S.W.7.

Glaxo Laboratories, Ltd.,
Greenford, Middlesex. June 25. H. B. HENBEST

\section{A. E. BIDF}

R. W. PEEVERS
P. A. WILKINSON

${ }^{1}$ Windaus, A., Lettré, R., and Schenck, F., Ann., 520, 98 (1935). :Brockmann, H., Z. physiol. Chem., 241, 104 (1936); 245, 96 (1937). - Inter alia I,insert, O., Z. physiol. Chem., 241, 125 (1936). Wunderlich. W., Z. physiol. Chem., 241, 116 (1936). Haslewood, G. A. D., Biochem. J., 33, 454 (1939). Butenandt, A., Hausmann, E., Chem. Soc., 64, 1900 (1942). Bergmann, W., Lyon, A. M., and Chem. Soc., 64, 1900 (1942). Bergmann, W., Lyon, A. M., and 'Haslewood, G. A. D., J. Chem. Soc., 224 (1938). Winterstein

$\checkmark$ For example, Milas, N. A. and Heggie, R., J. Amer. Chem. Soc.

60, 984 (1938). Mazza, F. P., and Migliardi, G., Chem. Abstracts, 87, 3762 (1943)
- Ziegler, K., et al., Ann., 551, 80 (1942).

\section{Antithyroid Drugs and Cytochrome Oxidase}

Schachner, Franklin and Chaikof ${ }^{1}$ found that the in vitro formation of diiodotyrosine and thyroxine by thyroid slices, using radioactive dine, $I^{131}$, as indicator is inhibited by cyanide, azide, sulphide and moxide (particularly in the dark). This indicates that the ytochrome oxidase system is involved in the synthesis of thyroxine by the thyroid gland. Franklin, Chaikoff and Lerner ${ }^{2}$, using the same thechnigue showed that thiourea and thiouracil in a concentration of $10^{-3} \mathrm{M}$ inhibited the in vitro synthesis of diodotyrosine and thyroxine

It has been repeatedly suggested that thiourea and thiouracil exert their antithyroid effect by inhibiting the cytochrome oxidase system in the thyroid gland. Paschkis, Cantarow and Tillson ${ }^{3}$, determining ytochrome oxidase activity colorimetrically with $p$-phenylene diamine $\mathrm{s}$ substrate, found that $0.002 M$ thiouracil added to thvroid in vitro inhibited the oxidase activity significantly. They also found a ignifleant decrease in the oxidase activity of the thyroids of adult rats fed thiouracil in the drinking water for 11-21 days. They state, however, that after several months treatment, the oxidase activity of the thyroids increases, approaching normal values. Stotz, Sidwell, and Hogness ${ }^{4}$ consider $p$-phenylene diamine to be not very suitable as a substrate for measuring cytochrome oxidase activity since its potential is so low that it is also oxidized by cytochrome $b$. Keilin and Hartree ${ }^{5}$, moreover, emphasize that results obtained using colorimetric methods for assessing cy tochrome oxidase activity should be accepted with reserve unless corroborated by measurements of oxygen uptake. The conclusion that thiouracil exerts its effect on the thyroid by inhibiting cytochrome oxidase activity is not supported by results obtained in these Laboratories.

The cytochrome oxidase activity of horse heart muscle preparations prepared according to Keilin and Hartree ${ }^{4}$ has been determined using hydroquinone, ascorbic acid and $p$-phenvlene diamine as substrates, the oxygen uptake being measured at $37^{\circ} \mathrm{C}$. over a period of acid were used as substrates, the activity was unaffected in the presence of a total concentration of $0.03 M$ thiourea, $0.03 M$ 2: aminopreviously incubated with the drug for several hours. Using $p$ phenylene diamine as substrate, however, the above concentration of thiouracil inhibited the activity 28-41 per cent. Thiourea and aminothiazole had no effect. Mann and Keilin ${ }^{6}$ have shown that sulphonamides, which also possess antithyroid activity, do not inhibit cytochrome oxidase activity, although Paschkis, Cantarow and Tillson ${ }^{3}$, using the procedure described above, found 30 per cent inhibition in the presence of $0.001 M$ sulphadiazine.

Since a large proportion of the total respiratory exchange of all organs is effected through the cytochrome oxidase system, the respiration-rate of tissue slices should be reduced by a substance which inhibits cytochrome oxidase activity. The respiration-rate of slices of hibits cytochrome oxidase activity. The respiration-rate of slices of
horse, dog and rat thyroids, however, is not affected by the addition horse, dog and rat thyroids, however, is not affected by the addition
of thiourea $(0.02 M)$ or thiouracil $(0.005 M)$. $\mathrm{Me}$ Moreover, the respiration-rate of diaphragm and liver slices from rats fed 0.5 per cent thiourea or 0.1 per cent thiouracil in the diet for several months is not significantly different from that of control animals. (The QOx. of thyroid slices from these rats is considerably greater than that of the controls, due pregreater than that to an increase in the proportion of the cellular components in hyperplastic rat the cellular

(II) 30 minutes in Warburg manometers. When hydroquinone and ascorbic thiazole or $0.003 M$ thiouracil even if the enzyme preparation was

If the activity of the cytochrome oxidase system of thyroid were inhibited by feeding thiourea or thiouracil, the proportion of the total respiratory exchange of thyroid slices which is cyanide-sensitive should be decreased. This is not the case with thyroid slices of either rats or dogs fed thiouract.

Results obtained with thyroid slices from one control dog and two dogs fed on a diet containing 0.1 per cent thiouracil for eight months are given in the accompanying table. The thyroid slices were suspended in $2 \mathrm{ml}$. Ringer phosphate solution at $p \mathbf{H} 7 \cdot 4$, with and without the addition of cyanide, and the oxygen consumption measured in an atmosphere of oxygen at $37^{\circ} \mathrm{C}$. in Warburg manometers over a period of 60 minutes. When $p$-phenylene diamine was used as substrate, $0.2 \mathrm{ml}$. of $0.2 M p$-phenvlene diamine adjusted to $p \mathrm{H} 7 \cdot 4$ was introduced into the side bottle and tipped into the main bottle at the end
of the first 60 -minute period. The oxygen consumption was then measured for a further 60 minutes.

RESPIRATION-RATE OF THYROID SLICES FROM CONTROL AND THIOURACILTREATED DOGS

\begin{tabular}{|c|c|c|c|c|}
\hline Diet & $\begin{array}{c}\text { No added } \\
\text { substrate } \\
\text { Qox. }\end{array}$ & $\begin{array}{c}\text { In presence of } \\
0.002 M \text { sodium } \\
\text { cyanide } \\
\text { Qox. \% inhibi- } \\
\text { tion }\end{array}$ & $\begin{array}{c}\text { aln pre } \\
0.018 M \\
\text { ene } \\
Q 0 x \text {. }\end{array}$ & $\begin{array}{l}\text { esence of } \\
\text { I } p \text {-phenyl- } \\
\text { diamine } \\
\% \text { of orig- } \\
\text { inal value }\end{array}$ \\
\hline $\begin{array}{l}\text { Control } \\
\text { Thiouracil }\end{array}$ & $\begin{array}{r}-3 \cdot 93 \\
-6 \cdot 90 \\
-5 \cdot 73\end{array}$ & $\begin{array}{l}-2 \cdot 35 \\
-4 \cdot 35 \\
-3 \cdot 22\end{array}$ & $\begin{array}{r}-8 \cdot 7 \\
-14.9 \\
-11 \cdot 7\end{array}$ & $\begin{array}{l}221 \\
216 \\
204\end{array}$ \\
\hline
\end{tabular}

These results show that the degree of inhibition of the respirationrate in the presence of $0.002 M$ sodium cyanide is not markedly different for thyroid slices from control and thiouracil-fed dogs. The ability to oxidize added $p$-phenvlene diamine is also not interfered with by feeding thiouracil.

Moreover, thiouracil $(0.005 M)$ added to slices of horse and dog thyroids does not inhibit the rate of oxidation of $p$-phenvlene diamine or ascorbic acid: in fact, in the case of horse and dog thyroid slices, the rate of oxidation of $p$-phenylene diamine is increased some $35-67$ per cent. 